\title{
Outcome of Patient with Moderate Functional Tricuspid Regurgitation Underwent Mitral Valve Replacement without Tricuspid Valve Repair
} Abd-Allah Abd-Alhamid Sallam, Mohammed Eldesoky Sharaa, Bahaa Abd-El Gawad Hassan El Khonezy, Mahmoud Hamed Al-Emam Zidan*, Mohammed Abd Elhameed Mohammed Cardiothoracic surgery Department, Faculty of Medicine, Al-Azhar University *Corresponding author: Mahmoud Hamed Al-Emam Zidan, Email: zizooo9492@gmail.com

\section{ABSTRACT}

Background: The tricuspid valve is often called the "forgotten valve" or "lost valve," because it is relatively understudied relative to the other cardiac valves. Left-sided valvular heart diseases represent the most common cause of functional tricuspid regurgitation (FTR) and the reported prevalence reached $25 \%$ to $30 \%$.

Objective: The aim of the work is to give an attention to the problem of moderate functional tricuspid valve regurgitation with mitral valve replacement and includes revision of anatomy of tricuspid valve, pathophysiology, diagnosis and management of functional tricuspid valve regurgitation.

Patients and Methods: In the present retrospective study, 30 randomly selected patients with moderate functional tricuspid valve regurgitation (grade 2) underwent mitral valve replacement for the first time at Al-Hussein University Hospital without repair of their moderate functional tricuspid regurgitation. The study was approved by the medical ethics committee of Al-Azhar University Hospitals and a written informed consent is obtained from all patients.

Results: In the present study and according to the sex, the females (9) represent (30\%) while males (21) were (70\%). Their age ranged between 40-60 years with mean $48.40 \pm 6.92$. The Degree of TR was mild $15(50.0 \%)$, moderate 6 $(20.0 \%)$, severe $3(10.0 \%)$ and Trivial $6(20.0 \%)$ of Echo data after 6 months.

Conclusion: Functional tricuspid regurgitation (TR) is commonly associated with mitral valve (MV) diseases and the presence of significant TR is reported to be an indicator of poor prognosis after the surgical correction of MV diseases. Keywords: Moderate functional tricuspid regurgitation, Mitral valve replacement, Tricuspid valve repair.

\section{INTRODUCTION}

The tricuspid valve is often called the "forgotten valve" or "lost valve," because it is relatively understudied relative to the other cardiac valves ${ }^{(\mathbf{1})}$.

Tricuspid valve regurgitation which can be divided into functional (secondary) disease and organic (primary) disease. Functional disease typically occurs in the setting of an anatomically normal valve and results from pulmonary artery hypertension and right ventricular (RV) dilatation. This condition most often is secondary to left-sided valvular disease but also may result from Eisenmenger's syndrome, RV infarction, or primary pulmonary hypertension ( $\mathrm{PPH})$. These types of disease typically manifest in the clinical presentation of tricuspid regurgitation (TR). Organic disease (in which there is a structural abnormality of the valve) is associated most frequently with rheumatic fever but also may occur in the setting of congenital anomalies, infective endocarditis, radiation therapy, trauma (from endomyocardial biop-sies or pacemaker lead insertion), carcinoid syndrome, Libman-Sacks endocarditis, eosinophilic leukemia, and diffuse collagen disorders. Left sided valvular heart diseases represent the most common cause of functional tricuspid regurgitation (FTR) ${ }^{(2)}$.

The reported prevalence of FTR in patient's undergoing operations for left-sided heart valve disease is $25 \%$ to $30 \%{ }^{(5)}$. Other study reported a prevalence of moderate to severe FTR of up to $63 \%$ of patients with mitral stenosis. The prevalence of moderate or severe FTR ranges largely from $8 \%$ to
$45 \%$ in patients undergoing MV surgery for mitral regurgitation (MR $)^{(3)}$.

Right ventricular (RV) dilatation and annular dilatation result in coaptation deficiency and tethering of leaflets of the tricuspid valve. Historically, conservative strategies have been recommended for FTR in patients undergoing left-sided heart valve operations ${ }^{(4)}$.

Guidelines have classified FTR based on anatomy, valve hemodynamics, hemodynamic consequences, and clinical symptom ${ }^{(5,6)}$. Concomitant tricuspid valve repair or replacement at the time of the left-sided valvular operation has been recommended, with class I indication in patients with severe FTR to improve long-term clinical outcomes ${ }^{(7)}$. Nonetheless, the optimal management of mild to moderate FTR remains controversial. We therefore performed a metaanalysis to examine the outcome of strategies used for the treatment of mild to moderate FTR in patients undergoing mitral valve operations.

\section{AIM OF THE WORK}

The aim of the work is to give an attention to the problem of moderate functional tricuspid valve regurgitation with mitral valve replacement and includes revision of anatomy of tricuspid valve, pathophysiology, diagnosis and management of functional tricuspid valve regurgitation.

\section{PATIENT AND METHODS}

- Ethical approval: This is retrospective study which was approved by the medical ethics committee of Al- 
Azhar University Hospitals and a written informed consent is obtained from all informed patients.

- Study population: patients with moderate functional tricuspid valve regurgitation (grade 2) underwent mitral valve replacement

- Patient's number: it is the study of 30 patients.

- Study venue: Al-Hussein University Hospital.

- Inclusion criteria: Patients with MVD requiring MVR for the first time with concomitant moderate functional tricuspid valve regurgitation and an intraoperative test of the tricuspid valve shows no regurgitation.

- Exclusion criteria:

1. Patients over 60 years old

2. Left ventricular systolic dysfunction (ejection fraction less than 50\%)

3. Redo mitral valve replacement

4. Ischemic mitral valve regurgitation

5. Organic tricuspid valve diseases

6. Patient with chronic pulmonary diseases

7. Mild or sever TVR

8. Patients had double valves lesions.

9. Intra-operative test of the tricuspid valve shows regurgitation.

10. Patient with impaired RV systolic function.

\section{Methods}

Patients were subjected to the following:

\section{1-Preoperatively:}

- History taking: a detailed history was taken, as regards the age, sex, functional class according to New York Heart Association (NYHA) classification.

- Clinical examination: a complete clinical and cardiac examination.

- Investigations:

Lab: CBC, LFTs, Pt, PC, INR, KFTs, FBS and serum electrolytes.

$>$ Electrocardiogram (ECG).

$>$ Radiological examination

- Plain chest x-ray

- Echocardiography

- Coronary angiography

\section{2- Operative data}

- Surgical approach for mitral valve.

- Total bypass time and aortic cross clamp time.

- Testing of tricuspid valve

- Intraoperative TEE

3- Postoperative assessment

1) Full ICU monitoring.

2) Time of mechanical ventilation.

3) Amount and rate of blood loss and need of reopening.

4) ICU medication and need for inotropic support.

5) Postoperative complication.

6) ICU stay.

7) Hospital stay.

8) Early postoperative echocardiography.
9) Six months follow up.

\section{Statistical analysis}

Recorded data were analyzed using the statistical package for social sciences, version 20.0 (SPSS Inc., Chicago, Illinois, USA). Quantitative data were expressed as mean \pm standard deviation (SD). Qualitative data were expressed as frequency and percentage.

The following tests were done:

- Paired sample t-test of significance was used when comparing between related sample.

- Chi-square $\left(x^{2}\right)$ test of significance was used in order to compare proportions between qualitative parameters.

- The confidence interval was set to $95 \%$ and the margin of error accepted was set to $5 \%$. So, the pvalue was considered significant as the following:

- Probability (P-value)

- P-value $<0.05$ was considered significant.

- P-value <0.001 was considered as highly significant.

- P-value >0.05 was considered insignificant.

\section{RESULTS}

In the present study and according to the sex, the females (9) represent (30\%) while males (21) were (70\%). Their age ranged between 40-60 years with mean $48.40 \pm 6.92$ Table (1).

Preoperative clinical assessment of the patients according to dyspnea rhythm, palpitation and lower limb edema classified them into Dyspnea NYHA class III 21 (70\%), class IV 9 (30\%); Rhythm AF 18 $(60.0 \%)$ and Sinus 12 (40.0\%); Palpitation 15 (50.0\%) and Lower limb edema 3 (10.0\%).

Table (1): Demographic data distribution of the study group.

\begin{tabular}{|l|l|}
\hline Demographic data & Total $(\mathbf{n}=\mathbf{3 0})$ \\
\hline Sex & \\
\hline Females & $9(30.0 \%)$ \\
\hline Males & $21(70.0 \%)$ \\
\hline Age (years) & \\
\hline Range & $40-60$ \\
\hline Mean \pm SD & $48.40 \pm 6.92$ \\
\hline
\end{tabular}

Preoperative echo data shows that the ranged of EF\% 53-79, with mean [67.70 \pm 8.38 ]; ranged of LVED (cm) 4.4-6 with mean [4.99 \pm 0.48 ]; ranged of LVES (cm) 2.5-4 with mean [3.20 0.52 ]; ranged of LA (cm) 4.5-8 with mean [5.56 \pm 0.91$]$; RV Dilated 3 (10.0\%) and Normal 27 (90.0\%); ranged of ESPAP (mmHg) 30-80 with mean [58.20 \pm 16.71$]$, the RHDM.R (30\%) and RHD-M.S (70\%) and all patients have moderate TR Table (2). 
Table (2): Echo data preoperative distribution of the study group

\begin{tabular}{|l|l|}
\hline Echo data preoperative & Total $(\mathrm{n}=30)$ \\
\hline EF\% & $53-79[67.70 \pm 8.38]$ \\
\hline LVED $(\mathrm{cm})$ & $4.4-6[4.99 \pm 0.48]$ \\
\hline LVES $(\mathrm{cm})$ & $2.5-4[3.20 \pm 0.52]$ \\
\hline LA $(\mathrm{cm})$ & $4.5-8[5.56 \pm 0.91]$ \\
\hline RV & \\
\hline Dilated & $3(10.0 \%)$ \\
\hline Normal & $27(90.0 \%)$ \\
\hline ESPAP $(\mathrm{mmHg})$ & $30-80[58.20 \pm 16.71]$ \\
\hline
\end{tabular}

Intra-operative TEE is done to all patients and show no significant TR. Also, intra-operative test is done to all patients through Rt atriotomy and open exposure of the TV assessing TV leaflets, calcification, annular dilatation and leaflet coaptation by pushing saline to the RT ventricle through the TV and closing the pulmonary artery by the sucker arm. There is good leaflet coaptation and no significant TR.

The early echo data results within one week postoperative shows the following: the mean of EF\% $56.60 \pm 6.39$; mean of LVED 4.80 \pm 0.54 ; mean of LVES 3.25 \pm 0.38 ; mean of LA 4.86 \pm 0.41 ; RV Dilated $3(10.0 \%)$ and Normal 27 (90.0\%); mean of ESPAP $38.80 \pm 10.77$; Degree of tricuspid regurge Mild 18 $(60.0 \%)$, Mild to mod $3(10.0 \%)$, Mod $6(20.0 \%)$ and Sever 3 (10.0\%) Table (3).

Table (3): Early postoperative echo data distribution of the study group

\begin{tabular}{|c|l|l|}
\hline & $\begin{array}{l}\text { Echo data } \\
\text { preoperative }\end{array}$ & Total $(\mathrm{n}=30)$ \\
\hline \multirow{4}{*}{ RV } & EF\% & $40-65[56.60 \pm 6.39]$ \\
\cline { 2 - 3 } & LVED & $4-5.9[4.80 \pm 0.54]$ \\
\cline { 2 - 3 } & LVES & $2.8-4.1[3.25 \pm 0.38]$ \\
\cline { 2 - 3 } & LA & $4.2-5.7[4.86 \pm 0.41]$ \\
\cline { 2 - 3 } & Dilated & $3(10.0 \%)$ \\
\cline { 2 - 3 } & Normal & $27(90.0 \%)$ \\
\hline \multirow{2}{*}{$\begin{array}{c}\text { Degree } \\
\text { of } \\
\text { tricuspid } \\
\text { regurge }\end{array}$} & $\begin{array}{l}\text { Mild to } \\
\text { moderate }\end{array}$ & $20-60[38.80 \pm 10.77]$ \\
\cline { 2 - 3 } & Moderate & $6(10.0 \%)$ \\
\cline { 2 - 3 } & Severe & $3(10.0 \%)$ \\
\hline \multirow{2}{*}{}
\end{tabular}

Six months post-operative studies: echo data shows that the ranged age EF 59.40 2.70 ; ranged age ED 4.74 \pm 0.37 ; ranged age $\mathbf{E S} 3.16 \pm 0.21$; ranged age $\mathbf{L A}$ $4.71 \pm 0.41$; RV Normal 30 (100.0\%); ranged age ESPAP (mmHg) 35.90 \pm 7.83 ; Degree of TR Mild 21 (70.0\%), Moderate $6(20.0 \%)$ and Sever $3(10.0 \%)$ Table (4).

Table (4): Echo data after 6 months distribution of the study group

\begin{tabular}{|l|l|}
\hline $\begin{array}{c}\text { Echo data after 6 } \\
\text { months }\end{array}$ & \multicolumn{1}{c|}{ Total $(\mathbf{n}=\mathbf{3 0})$} \\
\hline EF & $55-64[59.40 \pm 2.70]$ \\
\hline LVEDD & $4.2-5.4[4.74 \pm 0.37]$ \\
\hline LVESD & $2.7-3.5[3.16 \pm 0.21]$ \\
\hline LAD & $4-5.5[4.71 \pm 0.41]$ \\
\hline RV & \\
\hline Normal & $30(100.0 \%)$ \\
\hline ESPAP (mmHg) & $25-55[35.90 \pm 7.83]$ \\
\hline Degree of TR & \\
\hline Mild & $21(70.0 \%)$ \\
\hline Moderate & $6(20.0 \%)$ \\
\hline Severe & $3(10.0 \%)$ \\
\hline
\end{tabular}

As regard to post-operative complication: Bleeding 1 (3.3\%); Blood transfusion 3 (10.0\%); Arrythmia "AF" 12 (40.0\%); Low CO 3 (10.0\%) and Rt side failure 4 (13.3\%) Table (5).

Table (5): Postoperative complications distribution of the study group.

\begin{tabular}{|l|c|}
\hline $\begin{array}{c}\text { Post-operative } \\
\text { Complications }\end{array}$ & Total (n=30) \\
\hline Bleeding & $29(96.7 \%)$ \\
\hline No & $1(3.3 \%)$ \\
\hline Yes & $27(90.0 \%)$ \\
\hline Blood transfusion & $3(10.0 \%)$ \\
\hline No & \\
\hline Yes & $12(40.0 \%)$ \\
\hline Arrythmia & $18(60.0 \%)$ \\
\hline AF & \\
\hline No & $27(90.0 \%)$ \\
\hline Low CO & $3(10.0 \%)$ \\
\hline No & \\
\hline Yes & $26(86.7 \%)$ \\
\hline Rt side failure & $4(13.3 \%)$ \\
\hline No & \\
\hline Yes &
\end{tabular}

Table (6): The extent of the difference between early postoperative and after 6 months according to degree of tricuspid regurge in the study group

\begin{tabular}{|c|c|c|c|c|}
\hline $\begin{array}{c}\text { Degree of } \\
\text { Tricuspid } \\
\text { Regurge }\end{array}$ & $\begin{array}{c}\text { Early } \\
\text { Postoperative }\end{array}$ & $\begin{array}{l}\text { After } 6 \\
\text { Months }\end{array}$ & $\mathbf{x} 2$ & $\begin{array}{c}p- \\
\text { value }\end{array}$ \\
\hline Mild & $18(60.0 \%)$ & $15(50.0 \%)$ & \multirow{6}{*}{9.273} & \multirow{6}{*}{$0.046^{*}$} \\
\hline $\begin{array}{c}\text { Mild to } \\
\text { moderate }\end{array}$ & $3(10.0 \%)$ & $0(0 \%)$ & & \\
\hline Moderate & $6(20.0 \%)$ & $6(20.0 \%)$ & & \\
\hline Severe & $3(10.0 \%)$ & $3(10.0 \%)$ & & \\
\hline Trivial & $0(0 \%)$ & $6(20.0 \%)$ & & \\
\hline Total & $30(100 \%)$ & $30(100 \%)$ & & \\
\hline
\end{tabular}


postoperative and after 6 months according to degree of tricuspid regurge in the study group.

\section{DISCUSSION}

Several studies reported a prevalence of moderate to severe FTR of up to $63 \%$ of patients with mitral stenosis which ranges from $8 \%$ to $45 \%$ in patients undergoing MV surgery for mitral regurgitation (MR) ${ }^{(3)}$.

This study was conducted on 30 patients randomly selected as regard to age and sex; all have secondary (functional) tricuspid reurge with moderate degree of TR (grade 2 as detected by preoperative Echocardiographic assessment. All patients underwent mitral valve replacement for the first time at AlHussein University Hospital without repair of their moderate functional tricuspid regurgitation. As intra operative test show no tricuspid regurgitation.

\section{Preoperative Evaluation:}

In our study the females were $9(30 \%)$ and males were $21(70 \%)$, while age ranged between $40-60$ years with mean $48.40 \pm 6.92$.

The age groups in our study are younger than the age groups in other study by Kwan et al. ${ }^{(\mathbf{8})}$ where their mean age at surgery was 52.0610 .5 years among 79 patients. Preoperative clinical assessment of the patients according to dyspnea rhythm, palpitation and lower limb edema classified them into dyspnea III 21 (70\%), IV 9 (30\%); Rhythm AF $18(60.0 \%)$ and Sinus 12 (40.0\%); Palpitation 15 (50.0\%) and Lower limb edema $3(10.0 \%)$.

In other studies, like De Bonis et al. ${ }^{\left({ }^{9}\right)}$ who found dyspnea III, IV, palpitation and lower limb edema reached $43(51.2 \%)$, I13 (15.5\%), 17(20.2\%) and $17(20.2 \%)$ respectively.

In a study done by Kwan et al. ${ }^{(8)}$ dyspnea III reached $39(31.7 \%)$ in repair group, $35(31 \%)$ in nonrepair group, dyspnea class IV 13(10.6\%)in repair group, $5(4.4 \%)$ in non-repair group and palpitation was $116(94.3 \%)$ in repair group while it was $91(80.5 \%)$ in non-repair group.

Preoperative echo data shows that the range of EF was 53-79\%, with mean [67.70 \pm 8.38 ]; range of LVED (cm) 4.4-6 with mean [4.99 \pm 0.48$]$; range of LVES (cm) 2.5-4 with mean [3.20 \pm 0.52$]$; range of LA $(\mathrm{cm})$ 4.5-8 with mean [5.56 \pm 0.91$]$; RV dilatation in 3 (10.0\%) and normal among 27 (90.0\%); range of $\operatorname{ESPAP}(\mathrm{mmHg}) 30-80$ with mean $[58.20 \pm 16.71]$, the RHD-M.R was $(30 \%)$ and the RHD-M.S reached (70\%) with moderate TR.

In other studies, like De Bonis et al. ${ }^{(9)}$ LVEF was $31 \pm 6.4 \%$, LVEDD $(\mathrm{mm})$ was $66.9 \pm 7.57$ LVESD $(\mathrm{mm})$ was $50 \pm 7.29$, RV dysfunction was 17(20.2\%), ESPAP

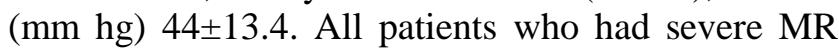
were, $41(48.8 \%)$ and those who had mild TR were 23 (27.3\%).

Bateman et al. ${ }^{(10)}$ reported in their study that LVEF was $55.9 \pm 9.7 \%$ in group A (repair group),
$58.3 \pm 9 \%$ in group B (non-repair group), LVEDD $(\mathrm{mm})$ was 56.6 \pm 9.7 in group A and 56.8 \pm 8.6 in group $\mathrm{B}, \operatorname{LVESD}(\mathrm{mm})$ was $39 \pm 8.1$ in group A and $38 \pm 6.8$ in group B, LA dimension $(\mathrm{mm})$ was $60.2 \pm 11.9$ in group $\mathrm{A}$, and $56.7 \pm 10.1$ in group B, ESPAP (mm hg) was $45 \pm 17.3$ in group $A$ and $35.5 \pm 14.7$ in group B. Also, in group A MR was 244(56.6\%), MS reached 129(29.9), mixed lesion was 58(13.5), mild TR was 150(34.8) and moderate TR was 281(65.2) while in group B MR was 260 (49.2), MS reached 182(34.5), mixed lesion was 86(16.3), mild TR was 495(93.8) and moderate TR was 33(6.3).

Intraoperative TEE: shows mild TR in all cases

Intra-operative test of TV: After mitral valve replacement and closure of the LA, removal of cross clamp, opening of the RT atrium, testing of annular dilatation, testing of tricuspid regurgitation by pushing saline under pressure through the TV and testing valve closure and leaflet coaptation.

\section{Early post-operative data:}

Our study shows that the mean of EF\% 56.60 \pm 6.39 ; mean of LVED 4.80 \pm 0.54 ; mean of LVES $3.25 \pm 0.38$; mean of LA $4.86 \pm 0.41$; RV Dilated 3 (10.0\%) and Normal 27 (90.0\%); mean of ESPAP $38.80 \pm 10.77$; Degree of tricuspit regurge Mild 18 (60.0\%), Mild to mod $3(10.0 \%)$, Mod $6(20.0 \%)$ and Sever $3(10.0 \%)$

In other study like Carpentier et al. ${ }^{(11)}$ LVEF (\%) 46.8 $\pm 17.6 \mathrm{~m}, \mathrm{RV}$ EF (\%) 43.3 \pm 7.7 , RV diameter (mm) $34 \pm 3.9$ and TR grade $2.6 \pm 0.5$.

\section{6 months post-operative studies:}

In our study the echo data shows that the ranged age $\mathrm{EF}$ was $59.40 \pm 2.70$; ranged age $\mathrm{ED}$ was 4.74 \pm 0.37 ; ranged age ES was $3.16 \pm 0.21$; ranged age LA was 4.71 \pm 0.41 ; RV normal was $30(100.0 \%)$; ranged age ESPAP $(\mathrm{mmHg})$ was $35.90 \pm 7.83$; degree of mild TR was $15(50.0 \%)$, moderate was $6(20.0 \%)$, severe reached $3(10.0 \%)$ and Trivial was $6(20.0 \%)$. In other study by Bateman $\boldsymbol{e t}$ al. ${ }^{(10)}$ echo data postoperative follow up range from (6-64 month) show LVEF was $56.5 \pm 9.2 \%$ in repair group (A) and $56.4 \pm 9.9$ in non-repair group (B), LVEDD (mm) was $57.2 \pm 9.7$ in group (A) and $58 \pm 9.7$ in group (B), LVESD (mm) was 39.1 \pm 7.4 in group (A) and $39.9 \pm 7.4$ in group (B), ESPAP(mm hg) was $40.2 \pm 14.6$ in group (A) and 39.5 \pm 17.4 in group (B). Among TR in group (A), 117 (81.3\%) had mild TR while 27(18.8\%) had moderate TR while in group (B) 117 (81.3\%) have mild TR while $27(18.8 \%$ ) have moderate TR.

De Bonis et al. ${ }^{(9)}$ reported that with median follow up 7.3 year last follow up echo data showed: LVEF was $36 \pm 10.9 \%$, LVEDD $(\mathrm{mm})$ was $60 \pm 8.4, \operatorname{ESPAP}(\mathrm{mm}$ hg) was $40 \pm 10.5$, RV dysfunction was $25(29.7 \%)$, secondary TR was absent or mild in 39 patients $(46.4 \%)$, moderate in 28 patients $(33.3 \%)$, moderately 
severe in 12 patients (14.2\%), and severe in 5 patients (5.9\%). Overall, 17 patients (20.2\%) had moderately severe or severe TR.

\section{CONCLUSION}

Functional tricuspid regurgitation (TR) is commonly associated with mitral valve (MV) diseases and the presence of significant TR is reported to be an indicator of poor prognosis after the surgical correction of MV diseases. Concomitant tricuspid valve (TV) repair or replacement at the time of MV surgery has been recommended in patients with severe functional TR to improve long-term clinical outcomes. Although TR can regress after successful MV surgery without TV repair. In our study more than $70 \%$ of patients show regression in tricuspid regeruge degree with less intra operative and post-operative complication and with less intraoperative mortality.

\section{REFERENCES}

1. Gray H, Standring $S$ (2005): Gray's Anatomy: The Anatomical Basis of Clinical Practice. 39th ed. Edinburgh, UK: Churchill Livingstone Elsevier; Pp. 1003-4.

2. Dreyfus GD, Corbi PJ, John CK (2005): Secondary TR or dilatation: which should be the criteria for surgical repair? Ann Thoracic Surgery, 32: 79-127.

3. Calafiore AM, Iacò AL, Romeo A et al. (2001): Echocardiographic-based treatment of functional tricuspid regurgitation. J Thorac Cardiovasc Surg., 142:308 -13.
4. Braun NS, Ross J, Morrow AG (1967): Conservative management of tricuspid regurgitation in patient's undergoing mitral valve replacement. Circulation, 35:63 -9 .

5. Kuwaki K, Morishita K, Tsukamoto $M$ et al. (2001): Tricuspid valve surgery for functional tricuspid valve regurgitation associated with left-sided valvular disease. Eur J Cardiothorac Surg., 20:577-82.

6. King RM, Schaff HV, Danielson GK et al. (1984): Surgery for tricuspid regurgitation late after mitral valve replacement. Circulation, 70:193-7.

7. Nishimura RA, Otto CM, Bonow RO et al. (2014): 2014 AHA/ACC guideline for the management of patients with valvular heart disease: executive summary: a report of the American College of Cardiology/American Heart Association Task Force on Practice Guidelines. J Am Coll Cardiol., 63:2438-88.

8. Kwan J, Kim GC, Jeon MJ et al. (2007): 3D geometry of a normal tricuspid annulus during systole: comparison study with the mitral annulus using real-time 3D echocardiography. Eur J Echocardiogr., 8:375-83.

9. De Bonis M, Lapenna E, Sorrentino F et al. (2008): Evolution of tricuspid regurgitation after mitral valve repair for functional mitral regurgitation in dilated cardiomyopathy. Eur J Cardiothorac Surg., 33:600-606.

10. Bateman MG, Quill JL, Hill AJ et al. (2013): The clinical anatomy and pathology of the human atrioventricular valves: implications for repair or replacement. J Cardiovasc Trans Res., 6:155-65.

11. Carpentier A, David HA, Farzan F (2010): Illustrations by Alain Carpentier and Marcia Williams Carpentier's reconstructive valve surgery. https://www.wikiwand.com/en/Alain_Carpentier 